\title{
POLÍTICA HABITACIONAL, REGULACÃO DO SOLO E ALUGUEL SOCIAL NO BRASIL
}

\author{
INTRODUÇÃO
}

\author{
Nelson Baltrusis* \\ Laila Nazem Mourad * *
}

A política habitacional no Brasil nunca privilegiou a locação como uma possibilidade. Apesar de ser um dos componentes básicos da atual política, optou-se pela propriedade da casa, e isso contribuiu para que as nossas cidades se esparramassem pela periferia, tornando-se entes ingovernáveis. $\mathrm{O}$ desejo da casa própria se tornou uma meta a ser conquistada por todos. Esse discurso hegemônico prevaleceu e ainda prevalece nos programas de habitação. Na verdade, a locação nunca foi entendida pelos governos, técnicos e os movimentos como solução para o déficit habitacional.

Considerando que a legislação de uso do solo, o zoneamento e os planos de desenvolvimento municipais devem ser mecanismos para regular o uso e

\footnotetext{
* Doutor em Arquitetura e Urbanismo. Professor adjunto do Programa de Pós-graduação em Planejamento Territorial da Universidade Católica do Salvador. Professor da Universidade Católica do Salvador. Pesquisador colaborador da Pontifícia Universidade Católica de São Paulo, Instituto de Estudos, Formação e Assessoria em Políticas Sociais

Av. Cardeal da Silva. 205. Cep: 40231902. FederaçãoSalvador - Bahia - Brasil.nbaltrusis@hotmail.com

* * Doutora em Arquitetura e Urbanismo. Bolsista de pósdoutorado PNPD-Capes. Membro do grupo de pesquisa Lugar Comum.

Rua Caetano Moura, 121, Sala de Pesquisa LUGAR COMUM. Cep: 40140-310. Ondina - Salvador - Bahia - Brasil.mourad.laila7@gmail.com
}

a oferta de terra urbanizada, essas regulações não demarcam espaço para locação, apesar de interferirem sobremaneira na configuração do espaço urbano, seja pelo seu cumprimento, seja por sua negação. Já que a configuração do espaço urbano e seus usos resultam de uma disputa pelas melhores localizações, dividindo-se o território hierarquicamentequanto mais poder melhor localização no espaço urbano-, caberia à União incentivar a utilização desse espaço para a criação de novos instrumentos de controle. E ela o fez realizando campanhas e apoiando a elaboração de Planos Diretores e Planos Locais de Habitação, embora se perceba que esse esforço do governo pouco tem repercutido.

A legislação municipal consolida a divisão entre ricos e pobres. No entanto, o que a cidade organiza, bem ou mal, o mercado, em busca de novas oportunidades, desorganiza. Nesse sentido, a disputa para ocupar uma posição melhor na estrutura urbana não para. Pelo contrário, se acirra. Na medida em que o espaço é uma arena privilegiada, nota-se uma disputa entre os diversos segmentos da sociedade, uma tensão visando a obter poder. Considerando que a urbanização é um processo no qual a força do mercado e as demandas sociais disputam o 
território da cidade, ao demarcar a cidade em zonas, estabelecendo padrões de uso e ocupação do solo urbano, a legislação está separando a cidade por funções e determinando valores diferenciados.

Essa lógica, que opera a produção de provisão para baixa renda, é perversa. A maior parte dos programas de habitação social é implantada nas áreas menos valorizadas do território, geralmente na periferia, carentes de infraestrutura e equipamentos. Entretanto, à medida que tais programas se incorporam à cidade, eles ganham valor, empurrando novos projetos para localizações mais distantes, num circulo vicioso. Algo semelhante acontece com os bairros populares autoempreendidos em loteamentos precários: à medida que se urbanizam, passam a se integrar à cidade e ganham valor. Essa forma de ocupação do solo, característica das grandes cidades brasileiras, foi amplamente descrita por Singer e Kowarick, tendo como base os loteamentos irregulares em São Paulo, desde a década de 1940. Kowarick denominou esse processo de espoliação urbana. Em outras palavras, o investimento feito pelo poder público para prover essas áreas periurbanas de infraestruturae serviços resulta na valorização deáreas vazias particulares entre a cidade urbanizada e o novo empreendimento, resultando numa apropriação privada indevida dos benefícios da urbanização (investimento coletivo). O proprietário de terra urbana retém lotes e até áreas inteiras aguardando uma maior valorização. Essa dinâmica produz, de um lado, uma cidade espraiada, cada vez mais preocupada em ampliar as fronteiras para além do município, de modo semelhante ao que ocorre em relação a Salvador e Lauro de Freitas; por outro lado, observa-se a existência de vazios urbanos.

Sabe-se que o déficit habitacional relativo era de 9,5\% em 2011 e que boa parte desse déficit se deve ao preço excessivo do aluguel (FJP, 2012). Estima-se que esse item seja responsável pelo aumento do déficit relativo pelo menos nas metrópoles de São Pauloe Curitiba. Em Salvador e Belém, houve uma diminuição do déficit. No entanto, o item ônus excessivo de aluguel cresceu em todas as regiões metropolitanas do país. A única exceção foi Porto Alegre.

Em 2012, os componentes com maior peso no déficit habitacional eram: o ônus excessivo com aluguel correspondendo a 2,660 milhões de unidades, ou seja, $45,9 \%$; a coabitação, com 1,865 milhões de domicílios ou $32,2 \%$; a habitação precária, com 883 mil, ou 15,3\%; e o adensamento excessivo em domicílios alugados, $382 \mathrm{mil} \mathrm{ou}$ $6,6 \%$. Somente na região Norte o componente domicílios precários tem um peso maior do que o ônus excessivo com aluguel.

De acordo com esses dados, parece-nos importante conhecer esse submercado de locação. Sabese que, muitas vezes, a política habitacional é responsável pela relocação de pessoas de áreas centrais para a periferia distante, inviabilizando, desse modo, o acesso às atividades econômicas, bem como às oportunidades e aos bens da cidade. Essa política cria vazios urbanos e imóveis subutilizados. Será que esses imóveis não poderiam ser destinados a programas de habitação e de locação social?

De acordo com uma apresentação do Ministério das Cidades, num seminário realizado no Uruguai e que tinha como tema a Locação Social: "Uma política bem sucedida deve oferecer diferentes soluções, o que inclui o chamado ciclo de vida, tornando a locação social uma excelente solução para jovens, migrantes recentes e idosos."

Essa questão vem à tona quando nos propomos a discutir uma política habitacional que incorpore a locação social. Sabemos o quanto é difícil trabalhar com esse tema num país onde a propriedade privada da terra e de imóveis é tida como uma recompensa, uma vitória pessoal dos trabalhadores, ainda que o acesso a essa moradia própria signifique morar na periferia, longe das áreas centrais e das oportunidades, ou em habitações precárias.

Este dossiê reúne alguns pesquisadores que se propõem a entender melhor como esse mercado se estrutura no país. Sabemos que compreender esse fenômeno é uma forma de contribuir para o desenho de uma política habitacional mais completa, que vise a atender a todos os estratos da população. Nele, trata-se o problema da habitação do ponto de vista das políticas de locação social, ou da falta delas, elegendo o tratamento que a legislação de uso do solo e o plano diretor dão a 
essa questão. Num primeiro momento, trataremos de caracterizar o problema habitacional com apoio nas diretrizes e ações do Plano Municipal de Habitação de Interesse Social (PMHIS). Em seguida, trataremos das políticas implementadas pelos governos dos estados e pelo governo federal, destacando a experiência do Programa de Arrendamento Residencial (PAR) e incorporando algumas considerações sobre o Programa Minha Casa, Minha Vida. Caracterizaremos o mercado de locação através do perfil de moradores e da dinâmica do mercado.

Iniciamos comLúciaBóguse Suzana Pasternak, que realizam um estudo do mercado de aluguel no Brasil, comparando domicílios e população moradora no Brasil em unidades próprias e alugadas. O trabalho de Camila D'Ottaviano pretende analisar os programas de locação social no âmbito da política de habitação de interesse social no Brasil, em especial, na cidade de São Paulo, a partir do Programa de Locação Social de 2002, e o projeto de lei $n^{\circ} 6.349$, de 2009, que tramita na Assembleia Legislativa Federal, propondo a criação de um Serviço de Moradia Social. Esse dossiê irá focalizar a caracterização das moradias alugadas no Brasil, e, em especial, nos municípios de São Paulo, Curitiba e Salvador. Em seguida Nelson Baltrusis e Laila Nazem Mourad procuram analisar a evolução da legislação urbana em Salvador e seus impactos na produção de habitação social. O texto de Tomas Antônio Moreira visa a explorar as políticas habitacionais nas últimas décadas para pautar o cenário atual da Política Habitacional de Curitiba. Para tanto se pautará no comportamento demográfico atual da região, as principais balizas e a estrutura do Plano Municipal de Habitação de Interesse Social, empreendido em 2008. E, por último, destaca-se o texto de Simaia do Socorro Sales das Mercês, Helena Lúcia Zagury Tourinho e Marco Aurélio Arbaje Lobo, que se propõem a iniciar uma discussão sobre a possibilidade de utilização da locação social como modalidade de provisão de moradia digna no Centro Histórico de Belém.

Acreditamos que os trabalhos aqui apresentados podem suscitar o debate sobre a questão da locação social no Brasil. Enseja-se que essa questão deixe de ser tratada marginalmente e passe a fazer parte, de fato, de uma política de habitação social.

Recebido para publicação em 01 de fevereiro de 2014 Aceito em 02 de março de 2014

Nelson Baltrusis - Doutor em Arquitetura e Urbanismo. Professor adjunto do Programa de Pós-graduação em Planejamento Territorial da Universidade Católica do Salvador. Professor da Universidade Católica do Salvador. Pesquisador colaborador da Pontifícia Universidade Católica de São Paulo, Instituto de Estudos, Formação e Assessoria em Políticas Sociais. Foi consultor do processo de elaboração de planos diretores participativos no município de Jandira pela Fundação para o Desenvolvimento da UNESP, FUNDUNESP e nos de Guarulhos, Vitória e Mogi das Cruzes pelo Instituto Pólis. Tem experiência na área de Planejamento urbano, atua principalmente nos seguintes temas: planejamento urbano, favelas, instrumentos urbanisticos, economia urbana e mercado imobiliario. Publicações recentes: Política Nacional de Habitação hoje. Produção de mercado com recursos do SBPE como ação dominante. Arquitextos (São Paulo), v. 1, p. 1, 2013; Transformações do modo de morar na metrópoles contemporâneas. Novos discursos, velhos problemas. Caderno CRH (UFBA. Impresso), v. 23, p. 50-75, 2010; Ricos e pobres, cada qual em seu lugar? a desigualdade sócio-espacial na metropole paulistana. Caderno CRH (UFBA. Impresso), v. 22, p. 135-149, 2009.

Laila Nazem Mourad - Doutora em Arquitetura e Urbanismo. Bolsista de pós-doutorado PNPD-Capes. Membro do grupo de pesquisa Lugar Comum. Tem experiência na área de Arquitetura e Urbanismo, com ênfase em política urbana, planejamento urbano e regional, plano diretor, plano estadual e municipal de habitação de interesse social, plano de bairro e processos de reabilitação em centro histórico. Publicações recentes: Movimentos de resistência ao processo de renovação conservadora do Centro Histórico do Salvador. In: José Rios Fernandes; Lúcio Cunha; Pedro Chamusca. (Org.). Geografia \& Política, Políticas e Planeamento. 1ed.Porto: GEGOT, 2013, v. 1, p. 1-788; Centro Histórico: planejamento para o turismo. In: Centro Gaspar Garcia de Direitos Humanos. (Org.). Moradia é Central: Lutas, Desafios e estratégias. 1ed.São Paulo: Centro Gaspar Garcia de Direitos Humanos, 2012, v. 1, p. 60-63; Lutas pela conquista do direito à moradia no Centro Histórico de Salvador. In: Edésio Fernandes; Betânia Alfonsin. (Org.). Revisitando o instituto do tombamento. 01ed.Belo Horizonte: Fórum, 2010, p. 01-468. 
